From Store Brands to Store Brandscapes:

The Emergence of a Time and Money Saving Heuristic

A. Collins, J. Cronin, S. Burt and R. George

Dr. Alan Collins. (Contact Author)

Department of Food Business and Development.

University College Cork.

Cork.

Ireland.

Dr. James Cronin.

Department of Marketing.

Lancaster University Management School.

Lancaster.

UK.

Professor Steve Burt

Institute for Retail Studies,

Stirling Management School - University of Stirling,

Stirling,

UK.

Dr. Richard George.

Haub School of Business.

Saint Joseph's University.

Philadelphia.

USA. 


\title{
From Store Brands to Store Brandscapes: The Emergence of a Time and Money Saving Heuristic
}

\begin{abstract}
Purpose: This research investigates role of store brands as a time and money saving heuristic in the context of an omnipresent store brand hierarchy. Drawing on the work of Tversky and Kahneman (1982) it proposes that the store brand hierarchy is characterised by many of the traits of frequently used heuristics employed by grocery shoppers.

Design/methodology/approach: Based on Chaiken's (1980) model of information processing and Stigler's (1961) perspective on the economics of information search, the study deductively establishes a model of store brand proneness to reveal the role of store brands as a time and money saving heuristic. The model is tested on a sample of 535 US households using structural equation modelling and subsequent multigroup analysis based on two sub-samples of households experiencing high financial pressure but who differ in terms of time pressure.
\end{abstract}

Findings: The findings provide strong support for store brands as a time and money saving heuristic and as a substitute for price search among households experiencing financial and time pressures.

Practical implications: Retailers need to be aware that extensions of the store brand portfolio beyond the traditional tiered hierarchy, risks undermining what has emerged to be a valuable heuristic used by certain shoppers. The hierarchy represents a risk to individual retailers in that as a heuristic, store brands have become part of a familiar generalised market wide store brandscape. Consequently, retailers are recommended to revaluate the precise role of store brands and the store brand hierarchy within their loyalty building strategies. In-store, store brands time and money saving characteristics may promote the subsitution of these products for branded competitors.

Originality/value: This study extends our understanding of the role of store brands in the marketplace by going beyond their traditional conceptualisation as a competitive device used by retailers, to instead view them as a decision-making tool used by consumers. It also deepens our understanding of the boundary between rational search activities and the transition to the use of frequently flawed heuristics within the shopping process.

Key Words: Store Brand Proneness; Brandscape; Hierarchy; Shopper Heuristic; Time Saving; Retail.

Article Classification: Research Paper 


\section{Introduction}

The development of store brands to become a strategic totem for a retailer's identity and quality reputation provides growing evidence of the continuing role of retailers in shaping consumers' experience of the shopping process (Burt, 2000; Cuneo et al., 2012; Dawes, 2013; Deleersnyder and Koll, 2012). Store brands, also termed private brands, private labels, or own labels are defined as the suite of products sold under a retail organization's house brand name and sold only through that retail organization's outlets (Morris, 1979). Gradually, the purpose of store brands has evolved to achieve multiple goals: from providing a defence against low price competition and the provision of a competitively priced alternative to national brands; to the establishment of points of differentiation based on innovation, reflecting a greater emphasis on the strategic development of the retailer as the brand (Burt and Davies, 2010; Collins and Burt, 2003). Over time, this has resulted in the emergence of a generic multi-tiered 'store brand hierarchy' that has become one of the most distinguishing features of the grocery retailscape today (Palmeira and Thomas, 2011; Geyskins et al, 2010; Nielsen, 2011; Rider, 2010). This is typically represented by a common strategy amongst retailers to offer at least two of their own branded offerings within the same product category across various price and quality tiers (e.g. a value tier representing the opening price point; a mid-priced tier of national brand equivalents; and a premium tier featuring unique and differentiating products) (PLMA 2011). While the effects of this well established generic system of store brands on manufacturers and retailers are widely understood, less is known about how availability and familiarity with multi-tier store brands impacts upon consumers.

A common thread throughout many studies of shopping behaviour within the retail context is the effort consumers invest in attempting to strike a balance between their desire for judgmental accuracy and their desire to minimalize effort expenditure (Mandrik, 1996) in the context of 'hyperchoice' (Mick et al, 2004; Chernev 2003). Familiarity thus becomes a welcome addition for consumers when interacting with the shopping environment; and it is within this logic that we believe the ubiquitous presence of multi-tier store brands plays an important role in the processing goals of effort reduction and value maximization. The specific purpose of this paper is to examine whether or 
not store brands have been appropriated by shoppers as a heuristic device; a mental stratagem capable of saving time and money. In doing so we explore the relationship between shoppers' store brand proneness and in-store price search.

Following Richardson et al. (1996) we define store brand proneness as a shopper's inclination to purchase store brand products, enabling us to adopt a more generalised market based view rather than a store, product or category specific approach (Erdem et al., 2004). More importantly, it enables us to nest the store brand purchase in the context of the broader shopping decision making process and to test whether or not store brands function as a time and money saving heuristic. By responding to Ailawadi and Keller's (2004) call for a greater understanding of the retail brand architecture, the paper contributes to the literature on the role of brands in the consumer marketplace as it extends our understanding of the store brand beyond a competitive device used by retailers and positions it as a decision-making tool used by consumers while shopping. It also deepens our understanding of the boundary between rational search activities and the transition to the use of frequently flawed time and cognitive saving heuristics within the shopping process.

To assess the time and money saving role of store brands, the study is situated in the context of the US grocery market where there is evidence indicating the presence of well-developed entrylevel and mid-price store brand tiers, both of which are shopped heavily by price-driven and valuecommitted consumers (see Nielsen, 2011). These tiers, we believe, are particularly important in terms of time and money saving motives especially when financial constraints are evident.

The paper is structured as follows. First it will outline the concept of a heuristic in the context of shopping behaviour before developing an a priori argument for store brands as a heuristic device for shoppers. Following this, the paper will establish a set of hypotheses that builds a model of store brand proneness which explicitly incorporates these products as a time and money saving device. This will be followed by an exposition of the method used to test the hypotheses in the form of two structural equations models, one based on the full survey of 535 US grocery shoppers, and a second based on two extracted cohorts of financially pressed shoppers who differ in terms of time pressure. 
The paper cloncludes with a discussion of the contributions, implications for management and future research and possible applications in markets characterised by a more sophisticated store brand hierarchy.

\section{Heuristics in Consumer Behaviour}

\section{Heuristics}

A heuristic may be defined as a mental stratagem that serves "to reduce the complex tasks of assessing probabilities and predicting values to simpler judgemental operations" (Tversky and Kahneman, 1982 p.3). Heuristics are cognitive rules of thumb that enable individuals to make decisions while reducing the information search which might otherwise be required to deal with existing conditions of uncertainty. The significance of heuristics to marketplace behaviour can be appreciated when considering the sprawling 'hyperchoice' of product options and category varieties that are encountered during most contemporary shopping trips, particularly in the grocery market. The time and effort consumers can be expected to invest in trying to make sense of the surplus of product information may have detrimental effects, including confusion and cognitive strain, as well as lower decision satisfaction (Mick et al., 2004). Heuristics make the grocery shopping environment manageable for consumers by reducing the amount of time and effort involved in making choices, and dealing with implicit trade-offs, while providing a certain level of comfort that the decision made will have a favourable outcome (Chaiken et al., 1989; Mandrik, 1996; Simpson et al., 2008).

There are a wide variety of heuristics and inferential mechanisms used by consumers to simplify decision making in daily life (for an extensive review see Kardes et al., 2004) some of which are particularly relevant in the context of grocery shopping. The brand-quality and price-quality heuristics dominate much of the marketing literature (Richardson et al., 1996; Völckner and Hofmann, 2007). The brand-quality heuristic enables consumers to deal with the uncertainty surrounding quality by helping them to manage perceived risk (Richardson et al., 1996) through reliance on a brand's accumulated equity as a quality cue (Delvecchio et al., 2006). This enables 
consumers to economise on search and mental effort "rather than considering tradeoffs between their usual brand and other available brands" (Nowlis 1995, p.288). Thus, national manufacturer brands with accumulated equity and ubiquity are regularly believed by consumers to be of superior quality and signal a "safer-bet" purchase during shopping missions (Aaker, 1996; Kirmani and Wright, 1989).

The inherent conflict within the price-quality heuristic, with price acting both as a measure of quality and as a measure of sacrifice, is widely recognized (Dodds et al., 1991; Scitovsky, 1945). Despite this, extant research demonstrates that price, or to be more specific, relative prices are used as a heuristic to complete product quality evaluations particularly when consumer motivation or involvement is low (Mitra, 1995). However considerations of relative prices can involve considerable effort given the array of price points, pack sizes and promotional activity available in the marketplace today. Furthermore, the efficacy of this heuristic may be questioned as it regularly exposes the consumer to substantial risks of overpayment or underperformance (Nowlis, 1995). Consequently consumers may have the incentive to devise and implement alternative heuristics that economise on price-quality evaluations and that reduce uncertainty on both the quality and sacrifice dimensions.

The 'representativeness heuristic' is based on similarity (Tversky and Kahneman, 1982). Predictions about an unknown product are inferred from what is known about another similar product or category: "An event is judged probable to the extent that it represents the essential features of its parent population" (Tversky and Kahneman, 1982 p.163). Additionally, the 'availability' and 'numerosity' heuristics have both been implicated in grocery shopping behavior and the determination of store price perceptions (Ofir et al., 2008). The availability heuristic refers to the ease with which experience of the phenomenon in question can be recalled from memory and can be influenced by recency, salience and frequency (Kardes et al., 2004) making it particularly relevant in the context of routine and familiar decision making situations such as grocery shopping. The numerosity or frequency heuristic on the other hand, relates to situations where shoppers employ their ability to recall more, rather than fewer, instances of the phenomenon on which to base their inferences (Alba $e t$ al., 1994; Alba et al., 1999). 


\section{Store Brands as a Heuristic Device}

Given the above, we argue that store brands most commonly sold in the context of a store brand hierarchy have the potential to act as a heuristic capable of reducing cognitive effort, time and monetary costs. In the first instance, store brands offer a solution to the overpayment underperformance risk (Nowlis, 1995) because the structural characteristic of the store brand hierarchy is imbued with more information than simply price alone. Consequently the hierarchy may serve as a more credible solution to the problem of asymmetric information because a given retailer's tiered positioning strategies are re-enforced by competitive discipline across the broader retail market. Second the generic store brand hierarchy, dimensioned by price and quality, acts as a rubric with inbuilt price/quality trade-offs that reduce the cognitive effort and time investments required of the shopper. Third, when considering the store brand hierarchy, the whole is greater than the sum of its parts. Recent findings indicate that the presence of a multi-tiered store brand hierarchy has the effect of improving quality perceptions within the hierarchy (Palmeira and Thomas, 2011) while evidence of shopping across the various tiers of the store brand hierarchy is provided by Geyskens et al. (2010) and across stores by González-Benito and Martos-Partal (2012). Fourth, a store brand heuristic may be a potent substitute for the representative, numerosity, and availability heuristics given the extensive variety of categories that feature these products, the frequency of purchase and the relatively low involvement normally associated with the purchase of many grocery items.

Finally, the hierarchical store brand structure typically occupies multiple product categories within a single store environment and is shared by many different grocery retailers. We thereby propose the ominpresence of a generic store brand hierarchy across different retailers can be loosely conceptualised as a brandscape (see also Sherry, 1998; i.e. a unified portfolio, positioning and merchandising of brands that becomes a familiar and comfortable space for consumers). By virtue of this familarity, consumers can interpret the context in which they are shopping, draw meanings from this context and economise on their search. The organization of retailers' store brand products according to shared, standardized, and recognizable price and quality points represents a basic blueprint that consumers can incorporate into their decision making and put to a wide variety of uses. 
As such, the wide availably of store brands and the near ubiquity of the basic store brand hierarchy across the grocery market may improve the shopping experience and yield efficiencies when used as a time and money saving device across multiple product categories and stores. A specific breakdown of our hypotheses is laid out below.

\section{Hypotheses and Model Development}

\section{Financial Pressure and Price Search}

The effect of financial pressure or perceived budget constraints (Urbany et al., 1996) is to reduce the consumer's consumption set. In economic analysis this is characterized by a shift in the individual's budget constraint which is constructed for a given nominal income and set of prices. One means of restoring the consumption set is to substitute search for other time consuming activities and identify lower prices. Thus we propose that in terms of the shopping experience;

H1 Household Financial Pressure will be positively related to In Store Price Search.

However the relationship between financial pressure and price search is partly determined by the dual and conflicting role of price as an indicator of product quality and a monetary measure of sacrifice (Scitovsky, 1945). This relationship is embodied in the shopper's willingness to trade down to lower perceived quailty products to take advantage of lower prices, thereby reducing financial pressure (Dodds et al., 1991). We propose that this propensity to trade-down will mediate the relationship between financial pressure and price search. Furthermore, the willingness to trade down increases the shopper's choice set encouraging price search at the point of sale. This suggests that;

H2 Household financial pressure will be positively related to the Willingness to Trade Down.

and

H3 Willingness to Trade Down will be positively related to In Store Price Search. 
While the relationship between store brand proneness and household income is mixed (see Baltas and Argouslidis, 2007; Hoch and Banerji, 1993) the relationship with financial pressure appears to be clearer. Ailawadi and colleagues (2001) found that store brand usage was positively related to the individual's financial constraints while more recent research links the purchase of store brand products to the economic cycle (see Lamey et al., 2012) supporting the view that store brands may be considered as inferior goods, as defined by economic theory, displaying a negative relationship with income levels. Thus we propose that financial pressure is one of the key drivers for store brand purchases and that;

H4 Household Financial pressure will be positively related to Store Brand Proneness.

Furthermore, given the substantial price discounts available throughout the store brand hierarchy, substitution of these products for national manufacturer brands or indeed alternative store brands within the hierarchy (Geyskens et al., 2010) enables shoppers to maintain their consumption bundle in the face of financial pressure. However knowledge and awareness of these discounts is acquired through the process of price search suggesting that:

H5 In Store Price Search will be positively related to Store Brand Proneness.

\section{Financial Pressures and the Opportunity Cost of Time Engaged in Price Search}

The propensity to employ heuristics when under time pressure is recognized throughout the literature (Mitchell and McGoldrick, 1996). The concept of time pressure is central to the understanding of decision-making and the use of heuristics. Time can be objectively measured but the concept of time pressure is more nuanced and of a subjective nature. It conveys the sense of tasks or activities to be accomplished relative to the time available and points to the time allocation decision given competing time demands. In this manner time pressure is related to the economic concept of the opportunity cost of time which may be defined as "the value of what was foregone in order for the individual to spend his or her time in the manner he or she did" (Bryant, 1990, p160). 
Throughout the economics literature, the opportunity cost of time is equated with and measured by the real wage rate (Bryant, 1990; Putrevu and Ratchford, 1997) which is the purchasing power of an hour's work. A fall in the real wage, either in light of a fall in the nominal wage or rising prices, is therefore associated with a fall in the opportunity cost of time. Consequently, the relationship between financial pressure and the opportunity cost of time is negative because as real wages fall, and financial pressure increases, the opportunity cost of time declines (Collins et al., 2012; Gauri et al., 2008). Alternatively, financial pressure may be due to unemployment or underemployment where the consumer is forced to consume excess leisure thereby reducing the opportunity cost of time engaged in price search. Thus we propose that;

H6. Household Financial Pressure is negatively related to the Opportunity Cost of Time engaged in Price Search

Our key concerns are the relationships between financial pressure, the individual's opportunity cost of time engaged in price search and store brand proneness. According to Stigler's (1961) cost-benefit perspective, consumers will engage in search as long as the marginal benefits exceed the marginal costs. In the current application, the primary resources being expended are time and effort and the benefits are denominated in terms of savings in the form of more economical store brands found through the process of price search. This suggests that the opportunity cost of time engaged in price search will partly determine the actual amount of search undertaken. As the opportunity cost of time engaged in search increases, the propensity to engage in search diminishes. Thus,

H7. The Opportunity Cost of Time engaged in price search will be negatively related to In Store Price Search.

However we need to modify this rational economising perspective to account for the possible use of heuristics as an alternative to search. Individuals who place a high value on their time, thereby experiencing a high opportunity cost of time, experience greater feelings of time pressure (Devoe and Pfeffer, 2011). To understand how time pressure might influence behaviour we turn to Chaiken's (1980) dual information processing framework which casts light on how time influences information 
processing and judgements. Central to this framework is the distinction between systematic versus heuristic information processing. According to the systematic view, agents engage in information processing and cognitive effort, while the heuristic view is associated with considerably less effort when making judgements. The perspective presents search and heuristics as alternatives. Expanding on this work, Kruglanski and Freund (1983) and Suri and Monroe (2003) find evidence showing that time pressure moderates the effect of incentives or motivation on the form of information processing employed. Where motivations or incentives are high, systematic information processing is favoured. However, where perceived time pressure and the opportunity cost of time is high, heuristic processing is more likely. This indicates that time pressure is likely to moderate the effect of financial motivations and determine the extent to which the individual engages in systematic or heuristic information processing in the course of making purchasing decisions. Earlier we proposed that store brand proneness is an outcome of price search where awarneness of discounts lead to purchase. We also argued that store brands in themselves have the potential to act as a time and money saving heuristic. Coupling these argments with the idea of time pressure or the opportunity cost of time as a moderator leads us to hypothesise that;

H8 Store brands act as a heuristic and there will be a direct positive relationship between the Opportunity Cost of Time engaged in Price Search and Store Brand Proneness.

More specifically, following the work of Suri and Monroe (2003) we propose that where financial pressures are high, the opportunity cost of time engaged in price search will moderate the nature of economising behaviours undertaken by the individual. Therfore;

H9: where Household Financial Pressure is high and the Opportunity Cost of Time is also high, consumers will engage in more heuristic information processing (incurring less cognitive and temporal costs) than consumers faced with high Household Financial Pressure but low Opportunity Costs of Time.

H10: where Houshold Financial Pressure is high and the Opportunity Cost of Time is low, consumers will engage in more systematic information processing/In Store Price Search (incurring 
more cognitive and temporal costs) than consumers faced with high Household Financial Pressure and high Opportunity Costs of Time.

Hypotheses 1-8 are presented in Figure 1.

\section{Locate Figure 1 near here.}

\section{Methodology}

\section{Data Collection}

Following much of the existing research in the area, direct self-reported measures were used for all the dependent and independent variables. Data were collected in the Pennsylvania, New Jersey, Delaware, and Maryland states using an external marketing company. This company was requested to build a sample size of 500 respondents from their database subject to the conditions that thirty percent of respondents were male, that the respondent was the individual responsible for the household's primary shopping, and had completed a grocery shop within the previous four weeks. Each qualifying respondent completed a 10 minute on-line survey and, to encourage responses, a $\$ 5$ reward was given for each completed questionnaire. Five hundred and thirty five completed questionnaires were usable. The number exceeded the initial 500 sample size request in order to meet the 30 percent male requirement and the additional observations are included in the analysis.

The variety of primary grocery stores frequented by the sample is presented in table $1.95 \%$ of the sample identifed a primary grocery location which sold store brands with at least two tiers of the store brand hierarchy available.

\section{Locate Table 1 Near Here}

\section{Measurement Model}


The indicators used for each latent construct in the model are presented in table 2. Items were chosen directly or modified from earlier works (Ailawadi et al., 2001; Lichtenstein et al., 1990; Putrevu and Ratchford, 1997; Urbany et al., 1996). A five point Likert scale anchored by $1=$ "strongly disagree" to 5 ="strongly agree" was used. One construct, the opportunity cost of time spent engaged in price search, employs a subset of items used by Lichtenstein and colleagues (1993) to measure price consciousness. We suggest that given our definition of opportunity cost of time spent engaged inprice search as the value of the most preferred opportunity forgone (e.g. leisure or remunerated work), the items selected are appropriate at a conceptual level. For example, instances where "searching for lower prices is not worth it", or where "looking for lower prices takes too much time", suggest that the opportunity cost of search (i.e. the value of the alternative) is high.

The use of self-reported measures, particularly when the dependent and independent variables are measured using the same scale can result in common methods variance (CMV). Following Podsakoff et al (2003), to assess this risk we first applied a Harmon's single factor test. The results of the exploratory factor analysis indicated that the one factor explained just over $25 \%$ of the variation in the data suggesting that CMV was not a problem. To extend our analysis beyond the one factor test we included a confirmatory factor analysis and introduced an additional latent variable. To estimate CMV each factor loading between it and every manifest variable was set to be equal (Podsakoff et al, 2003). The factor loadings for this CMV variable were estimated as 0 providing further evidence that our data is free of common methods variance.

Initially, a maximum likelihood confirmatory factor analysis was carried out using AMOS 20 to test the measurement model. The overall model fit measures, chi-square $\left(\chi^{2}\right)=131$, degrees of freedom (d.f.) $67, p=.000$, the goodness of fit index GFI=. 97, the adjusted goodness of fit index AGFI=.96 are presented in table 2 . The Chi-square is significant at the .001 suggesting a lack of fit. However the Chi-square is very sensitive to large sample sizes making it very probable that some inconsequential difference will be found between the variance-covariance matrix and the implied variance-covariance matrix hypothesised in the measurement model. Consequently we employ the comparative fit index $(\mathrm{CFI}=.974)$, the Tucker-Lewis index $(\mathrm{TLI}=.965)(\mathrm{Hu}$ and Bentler, 1999) and 
root mean square error of approximation (RMSEA $=.042)$ to assess the model's fit (Byrne, 2001). All support an acceptable model fit (Arbuckle, 2012). All standardized factor loadings demonstrate the correct sign and statistical significance $(\mathrm{p}<.001)$ on their corresponding construct.

\section{Locate Table 2 Near Here}

Convergent validity was assessed by examining the size and significance of the factor loadings and their associated critical values as well as inspecting the average variances extracted (AVE) for each construct (table 2). All average variances extracted met the .50 threshold (Hair et al., 1995) and all items significantly and positively loaded on their corresponding latent construct demonstrating adequate convergent validity. Reliability is demonstrated through the use of Cronbach's alpha scores with all constructs meeting the desired .70 threshold (Nunally, 1981) along with the Spearman-Brown value for the two item willingness to trade down construct. Discriminant validity is supported by table 3 and the fact that the average variance extracted exceeds the squared correlation coefficient for each pair of latent factors (Fornell and Larcker, 1981).

Consequently the measures of the constructs used in our model achieve satisfactory reliability, convergent and discriminant validity.

\section{Locate Table 3 Near Here}

\section{The Results: Hypotheses 1-8}

The structural model outlined in figure 1 was tested and estimated using AMOS 20. The results are presented in table 4 . Once again the chi-square is significant at the .001 percent level (Chi-square $(\chi 2)$ $=132.99$ d.f. $=69, p=.000$ ) due to sample size so we rely on the remaining measures of fit (GFI.97), $(\mathrm{AGFI}=.97),(\mathrm{CFI}=.98),(\mathrm{TLI}=.97)$ and the root mean square error of approximation, $(\mathrm{RMSEA}=$ .042). All indicate a good level of fit for the overall model (Arbuckle, 2012; Byrne 2001). Therefore we can proceed to examine our model in detail.

First, the model explains $29 \%$ of the variation in store brand proneness. We believe that this is acceptable given that other factors such as perceived risk have not been incorporated and compares 
well with other models that included considerably more variables (Urbany et al., 1996). The results present the hypothesised paths and direction of each coefficient and the estimated standardised coefficient values with their significance levels and the critical ratios. They provide support for all the direct relationships postulated with the exception of the direct relationship between household financial pressure and store brand proneness.

To establish a competing model, the most important causal path as far as this research is concerned, between the opportunity cost of time engaged in price search and store brand proneness, was removed. This relationship, we have argued captures the essence of store brands as a heuristic. The model was re-estimated yielding a Chi-square $(\chi 2)=144.7$ d.f. $=70, p=.000$. (AGFI=.94), (TLI= .97). The change in Chi-square $\Delta(\chi 2)$ for 1 degree of freedom $=11.71$ is significant at the .001 level indicating a significantly inferior model fit. This is supported by the fall in the AGFI and an increase in the Akaike Information Criteria from 204.997 to 214.736 (Byrne, 2001). Consequently, we can be confident that the causal path between the opportunity cost of time engaged in search and store brand proneness improves model fit.

\section{Locate Table 4 Near Here}

To provide more insight, and extend our findings beyond the hypotheses, the results are

further broken down into the total, direct, and indirect effects in table 5. Focusing on household financial pressure (HFP), we note that while its direct effect on store brand proneness (SBP) is small and insignificant we can observe that its total effect (.213), mediated through the willingness to trade down to lower quality goods for better prices (WTD), in-store price search (ISPS), and the opportunity cost of time engaged in search (OCTS) is substantial. As shown in table 4, the direct effects between HFP and each of these variables, ISPS $(\beta=.242)$, WTD $(\beta=.289)$, and OCTS $(\beta=-.271)$ are all significant and display the expected signs. Thus HFP is deeply implicated in SBP but the mediated nature of its relationship may explain some of the contradictory results found in earlier research which focused on the direct relationship between income and store brand proneness.

In line with earlier related research, our view that willingness to trade down (WTD) would be 
found to be positively related to in store price search (ISPS) is supported. We can see that there is a positive indirect effect between WTD and SBP mediated through ISPS (table 5). This finding sits neatly with the earlier work of Richardson and colleagues (1994) who observe that evaluating perceived quality is a complex task involving a wide variation of intrinsic and extrinsic product attributes at different price points. Thus WTD increases the shoppers' choice set, providing the shopper with the motivation to search for lower prices, and upon discovery encourages the purchase of store brands. The direct effect between ISPS and SBP is the largest of all such effects $(\beta=.600)$ highlighting the importance of in store price search and price comparison across brands in explaining store brand proneness.

\section{Locate Table 5 Near Here}

Turning our attention to the set of relationships between the opportunity cost of time in searching(OCTS), in store price search (ISPS), and store brand proneness (SBP) sheds light on the main contribution of this research. As table 5 shows, the total effect between OCTS and SBP is extremely small $(\beta=-.044)$, suggesting that the opportunity cost of time spent engaged in search is not a determinant of store brand proneness. However this total effect is comprised of two pathways, each of which has very different dynamics. First, following the systematic information processing path, the direct effect of OCTS on ISPS is negative, significant, and large; as OCTS increases less search is undertaken, depressing store brand proneness. The indirect effect between OCTS and SBP, mediated through ISPS, may be calculated as the product of both direct effects (i.e. $-.410 * .60=-.246$ ). On the other hand we have proposed the use of store brands as a heuristic, a time and effort saving device modelled as a direct path between OCTS and SBP, is found to be positive and significant $(\beta=.202)$. The total effect between OCTS and SBP, calculated the sum of these effects is small as these effects almost cancel each other out $(-.246+.202=-.044)$.

To investigate these relationships, and establish clearer evidence for systematic versus heuristic information processing and their effects on store brand proneness we progress to hypotheses 9 and 10. 


\section{The Results: Hypotheses 9-10}

\section{Measurement Invariance}

To test hypotheses 9 and 10 and establish the role of the opportunity cost of time in price search (OCTS) on systematic versus heuristic information processing required two cohorts of respondents with a similar motivation (Household Financial Pressure) to save money but different resources in terms of time measured by OCTS; a cohort comprised of individuals under financial pressure with a high OCTS and another cohort comprised of individuals also under financial pressure but with a low OCTS. To establish these cohorts, latent means were extracted from AMOS using the measurement model. The means for OCTS and HFP were used as the clustering variables for a hierarchical cluster analysis using Ward's method. A four cluster solution was extracted. The means for each cluster are provided in table 6 . To test hypotheses 9 and 10 two clusters were chosen for multigroup analysis:

Cluster 1, characterised by higher than average HFP but lower than average OCTS;

Cluster 3, higher than average FP, with a higher than averge OCTS.

\section{Locate Table 6 Near Here}

To test $\mathrm{H} 9$ and $\mathrm{H} 10$ we need to establish the measurement basis for comparing our two cohorts. There is a hierarchy of increasingly demanding nested levels of measurement equivalence (Steenkamp and Baumgartner, 1998; Vandenberg and Lance, 2000). The level of measurement equivalence required for a specific piece of analysis is determined by the parameter of interest (e.g. regression coefficients, means). For the purposes at hand we are interested in differences in regression coefficients or structural paths between our two cohorts. Thus, metric equivalence which guarantees cross group equality of the intervals of the scales used to measure our latent constructs is required given our specific application (Davidov et al., 2014). The existence of metric equivalence is tested by fixing the factor loadings between the manifest and latent variables across groups yielding our constrained model and assessing the difference in fit between this and the unconstrained model when factor loadings are allowed to vary across cohorts (freely estimated). 
The initial analysis showed that invariance could not be established for the willingness to trade down (WTD) construct so this was removed from the analysis. This was not considered problematic as this construct was not central to hypotheses 9 or 10.

Having removed this construct, the remaining constructs and manifest variable were tested across both cohorts. The Chi-square $((\chi 2)=102.53$ d.f. $=96, p=.305)$ for the unconstrained model when compared to the constrained measurement model ( Chi-square $(\chi 2)=128.83$ d.f. $=104, p=.05$ ) yielded a change in Chi-square $\Delta\left(\chi^{2}\right)=26.30$ for $\Delta \mathrm{df}=8$. This exceeds the Chi-square $\left(\chi^{2}\right)$ with $\mathrm{df}=8$ $=15.507$ at $\alpha=0.05$ level, indicating a significant difference between the unconstrained and constrained measurement models.

Two items, Pcom1 and HF1 were found to be the causes of the difference. Following Byrne and Van De Vijver (2010), these were removed retaining only the equivalent items which was sufficient for our analysis (Byrne et al., 1989; Davidov et al., 2014). A comparison of the revised unconstrained model (Chi-square $(\chi 2)=44.92$ d.f. $=58, p=.896)$ and the constrained measurement model1 (Chi-square $\left(\chi^{2}\right)=53.115$ d.f. $=64, p=.832$ ) yields a change in Chi-square $\Delta\left(\chi^{2}\right)=8.19$ for $\Delta$ d.f. $=6$ which is not significant at $\alpha=0.05$ level (i.e. is less than (Chi-square $(\chi 2)=12.592$ d.f. $=6$ ), indicating no difference between our models and supporting invariance at the metric level.

\section{Comparisons across Groups}

Having established metric invariance and fixing the factor loadings associated with each construct, the next stage was to test the revised structural model presented in figure 2 . To test our hypotheses we estimated the revised model and the results are presented in table 7 . By comparing constrained model 1 , where factor loadings are fixed but the structural parameters (path coefficients) are freely estimated, with constrained model 2 where both factor loadings and structural paths are fixed, we find a change in Chi-square $\Delta\left(\chi^{2}\right)=30.01$ for $\Delta \mathrm{df}=6$ or equivalently $\Delta\left(\chi_{2}\right)=5.16$ for $\Delta$ $\mathrm{df}=1$. Examining a Chi-square distribution table reveals that for 1 degree of freedom, the Chi-square $\left(\chi_{2}\right)$ at $\alpha=.05=3.841$. Any Chi-square $\left(\chi_{2}\right)$ greater than this value for $\Delta \mathrm{df}=1$ indicates a significant 
difference. This result indicates a reduction in model fit and that differences exist in the structural paths (regression coefficients) across our two cohorts.

\section{Locate Figure 2 Near Here}

To identify the cause of this reduction in fit (and the structural paths that differ across cohorts) we now begin to freely estimate the structural paths (our regression coefficients) in a nested sequential manner.

By freeing the structural path between the opportunity cost of time in price search (OCTS) and store brand proneness (SBP), and examining the change in Chi-square $\left(\chi_{2}\right)$ between the constrained model 2 and semi constrained model 1, we can isolate the effect on model fit thereby identifying if the strength of this path differs across both our cohorts. The change in Chi-square $\Delta$ $(\chi 2)=5.446$ for $\mathrm{d} . \mathrm{f}=1$, indicates a significant difference and an improvement in model fit compared to the constrained model 2, providing evidence that the strength of this relationship differs across the two cohorts.

We now add the structural path between opportunity cost of time in price search (OCTPS) and in store price search (ISPS) to our freely estimated structural parameters (semi constrained model 2). Comparing semi constrained model 2 with semi constrained model 1 reveals a change in Chisquare $\Delta\left(\chi^{2}\right)=9$ for 1 d.f., strongly supporting an improvement in the overall model fit and a significant difference in the strength of this path across both cohorts. The overall improvements in our model as the relevant paths are freed are supported by the declining AIC criteria (Byrne, 2001).

Next, we add the structural path between in store price search (ISPS) and store brand proneness (SBP) to our freely estimated structural parameters (semi constrained model 3) and note that the change in Chi-square $\Delta\left(\chi^{2}\right)=.04$ for 1 d.f. does not support any difference in the relationship between ISPS and SBP across the cohorts. This we suggest indicates that both cohorts respond to changes in price search undertaken in the same manner.

\section{Locate Table 7 Near Here}


Having established that differences exist in the strength of the OCTS $\rightarrow$ SBP (heuristic processing) and OCTS $\rightarrow$ ISPS (systematic processing/price search) paths across cohorts, we now progress to examine the path coefficients to investigate if evidence can be found to support $\mathrm{H} 9$ and H10. To recap,

H9: where financial pressure is high and the opportunity cost of time is also high, consumers will engage in more heuristic information processing (incurring less cognitive and temporal costs) than consumers faced with high financial pressure but low opportunity costs of time.

H10: where financial pressure is high and the opportunity cost of time is low, consumers will engage in more systematic information processing/price search (incurring more cognitive and temporal costs) than consumers faced with high financial pressure and high opportunity costs of time.

The results are presented in table 8 . It shows that the path between opportunity cost of time in price search (OCTS) and store brand pronesses (SBP) is positive and significant for those with a high OCTS. For these shoppers, store brands help economise on time and effort while dealing with the challenge of financial pressure. We note that the path is not significant for those with a low OCTS providing clear support for $\mathrm{H} 9$ and heuristic information processing.

Examining the path between opportunity cost of time in price search (OCTS) and in store price search (ISPS) reveals support for H10, with those shoppers with a low OCTS engaging in ISPS. However, no evidence is found to support this relationship for shoppers with a high OCTS.

\section{Locate Table 8 Near Here}

\section{Discussion and Theoretical Implications}

There is a convincing body of research that ties store brand penetration and sales to the economic cycle and the financial wellbeing of households (Ailawadi et al., 2001; Lamey et al., 2012). Much of the extant work has suggested direct relationships between financial circumstances and store brand proneness. The results that emerge from the current study do not support such a direct 
relationship but indicate that household financial pressure causes a change in how households evaluate time with implications for information acquisition, processing and purchasing behaviours. Household financial pressure also causes changes in preferences that lead shoppers to become more willing to forgo quality and seek out lower prices. In this manner, the importance of the mediating effects of shoppers' opportunity cost of time engaged in price search and changing preferences on household financial pressure have been brought to the fore.

In combining Chaiken's (1980) model of decision making and more recent developments incorporating time pressure (Suri and Monroe, 2003) with the more orthodox marginal cost - marginal benefit decision making as espoused by Stigler (1961), this research provides a more inclusive perspective on decision making when both time and money are scarce. It draws attention to the boundary where incentives are mediated by a lack of time and when further search is economically irrational to the world of heuristics where decision making is simplified but frequently flawed. It is in this space that store brands and the store brand hierarchy can serve as a uniquely effective heuristic.

By extending beyond financial matters, this research has uncovered the subtle processes initiated by financial stress that cause shoppers to re-evaluate how they allocate their time and how they deal with time scarcity. One of the most striking findings to emerge from this research is that at an aggregate level, we saw that the opportunity cost of time in price search appeared to have little effect on store brand proneness. Importantly, our analysis revealed that this was the outcome of two distinct and counteracting effects. Richardson et al. (1994) and Baltas et al. (2010) argue that search is a time consuming process involving evaluations of various forms of perceived risks and price comparisons. These evaluations require effort and time and are cognitively demanding (Chernev, 2003; Garbarino and Edell, 1997). Traditional economic theory (Stigler, 1961) informs us that rational shoppers would be expected to engage in price search until the marginal benefits coincide with the marginal costs or, put in another way, as long as it's worth it. This fitted neatly with the systematic information processing strand of Chaiken's (1980) dual information framework. However drawing on the subsequent works of Kriglanski and Freund (1983) and Suri and Monros (2003) enabled us to incorporate Chaiken's heuristic strand as a response to time scarcity and to progress beyond this 
limited economic view of behaviour. By considering both strands simultaneously we were able to isolate the discriminating effect of time on search and how financially pressed shoppers facing high time constraints had a propensity to use store brands as a money and time saving heuristic.

There is a tendency within much of the existing literature on store brands to adopt either a store, category or tier specific perspective. The current work, by explicitly considering and interpreting store brands as ubiquitous, familiar, subsitutable, transferable, and recognisable market offerings that are commonly sold in the context of an established structured price-quality hierarchy (which we have referred to as a store brandscape) points to their role as a time and money saving heuristic with ever increasing applicability. We argue that the store brand hierarchy itself incorporates features of the brand-quality, price-quality, representiveness, numerosity and availability heuristics; it provides a price-quality rubric that acts as a guiding mechanism to rationalise and simplify shoppers' decision making processes within and across categories and across stores. Of added benefit is that while many frequently used heuristics expose shoppers to the dangers presented by asymmetric information (Lindsey-Mullikin and Petty, 2011; Srivastava and Lurie, 2001; Urbany et al., 1988) the store brand hierarchy is more reliable and protected from opportunistic behaviour on the part of the retailer through market enforced disciplines including reputational effects and associated incentives, and more market wide competitive forces.

In this context this research has extended our theoretical understanding of the tiered store brand structure beyond recognition of this architecture as simply a marketing tool used by retailers. While the tiers of the store brand hierarchy are purposefully aligned by retailers to compete with rivals in the marketplace, we have built the case that this hierarchy also operates in the consumer's mind as a 'buying tool' to facilitate an easier shopping experience. As a buying tool, store brands presented in the form of a generic hierarchy offer more to shoppers than the sum of the tiers. Evidence of this is provided by Palmeira and Thomas (2011) regarding quality perceptions. The heuristic nature of the hierarchy bolsters our understanding that the familiarity and ubiquity of a portfolio of store brands (i.e. a brandscape) can help orient and simplify consumers' experiences in the marketplace (see also Rahman and Cherrier, 2010) and also helps redress some of the problems created by hyper 
choice in a store setting (Mick et al., 2004).

\section{Managerial Implications}

First, retailers need to be aware that the effect of financial pressure on store brand proneness is mediated through changing preferences, shoppers' opportunity cost of time, and their propensity to check prices. Our findings indicate that changing financial pressure influences customers' willingness to trade down and, as a consequence of price search, display a greater propensity to purchase store brands. While this finding may be encouraging, retailers need to be aware that this trading down may occur within the store brand hierarchy resulting in cannibalisation. Consequently, management may need to consider their promotional activity within the store brand hierarchy to ensure that shoppers continue to see their mid and premium tiers (where available) as delivering ongoing value.

Second, for a given level of financial pressure, our results suggest that the opportunity cost of time will determine the extent to which shoppers engage in price search or employ the store brand heuristic. Those with a low opportunity cost of time engage in more price search. For these individuals, searching or hunting for lower prices may even prove to be an enjoyable aspect of the shopping process (Collins et al, 2014); and if linked to store brand products, create an additional source of hedonic value adding positively to the shopping experience (Babin et al, 1994) and the retailer as a brand.

Third, the findings suggest that it is important that retailers concentrate on the formulation and maintenance of a clear and simplistic brandscape that consumers can decode and use as a heuristic. A heuristic, by definition is a time and effort saving device. In a consumer market increasingly characterised by demands for convenience (in all its forms) any heuristic meets these demands. Our findings suggest that a clear, generic, and commonly understood store brand hierarchy provides such a heuristic. To this end, it suggests that retail management should step back from individual tiers and develop an understanding of the value that the overall store brand hierarchy as an

entity creates. Recent trends in store brand evolution such the expansion of retailers' role as brand creators (Witham, 2013) risks diverting important attention away from the existing store brand 
hierarchy. To facilitate shopping within their brand hierarchy, retailers might be advised to preserve the clear price-quality rubric lest the hierarchy becomes confused with a proliferation of venture brand type products (IGD, 2012). Furthermore by drawing retailers' attention to the time saving function of the store brand hierarchy, other means of providing time savings including siting instore and merchandising techniques such as logical product adjacencies may be identified to increase the time efficiency of shoppers' product selection processes. This may be of particular importance in the case of convenience or fill-in shopping missions where the opportunity cost of time may be particularly high.

Fourth, there is the matter of loyalty. Earlier authors investigating the relationship between store brand proneness and loyalty found the relationship to be linear. However there is evidence of consumers generalising their shopping experience across retailers with store brands becoming increasingly substitutable (Szymanowski and Gijsbrechts, 2012). Ongoing research is revealing the relationship to be non-linear, nonmonotonic, reflecting an inverted U shape. Ailawadi and colleagues (2008) explained this by arguing that highly store brand prone individuals are attracted more by savings rather than a particular store brand and consequently shop for best prices across stores. This we suggest may be related to systematic information processing where additional temporal costs are incurred for monetary savings. González-Benito and Martos-Partal (2012) found a similar non-linear relationship between store brand proneness and loyalty, but interestingly observed that the loyalty relationship endured for longer in limited line discounters. We add to the interpretation of this work and propose that shoppers' choice of limited line discount stores, which tend to rely almost exclusively on store brands, may be another aspect of time, money and cognitive economising and is consistent with heuristic driven store brand buying behaviour that we have uncovered.

Finally, the challenge for each retailer is to determine the precise role of store brands and the store brand hierarchy within their loyalty building strategies. The hierarchy represents a risk to individual retailers to the extent that store brands as a heuristic have become part of a familiar generalised market wide store brandscape that is substitutable and transferable. This suggests that store brands may not possess the loyalty building qualities previously imagined yet, once the shopper 
is in-store their heuristic qualities may serve to encourage the substitution of store brands for national brands thereby improving the financial return to the retailer. The implication is that retailers may have to focus their loyalty building efforts elsewhere.

\section{Areas for Further Research}

An important question that emerges from this work is the need to add further detail to the relationship between store brand proneness and time pressure within the context of different shopping occasions and missions. We have shown empirically that store brands act as a heuristic. We have argued that this heuristic can be applied both within stores and across the broader store brandscape. However, determining the extent to which the heuristic is actually applied in different shopping situations was beyond the data available in this study.

The data underlying this research comes from the US market where the value and mid priced components of the store brand hierarchy are well developed and the relationship between financial pressure, price search and store brand proneness may be more established when compared with Europe. It is clear that the 'third' or 'premium' tier of the store brandscape has evolved to a much greater extent in Europe, particularly in the UK market, where quality concerns may be of relatively greater importance when shopping the store brand hierarchy. This opens up the possibility that the heuristic potential of the store brandscape may extend beyond time engaged in price search to include economising on time and effort spent engaged in strategies to reduce perceived risk (Richardson et al 1994, Gonzales-Mires et al, 2006) and assessing product quality across brands. We believe that this merits further investigation.

Finally, to progress and deepen this line of research, experimental design based work might be considered to test the extent to which the heuristic is used as an alternative to evaluating the pricequality bundles offered by the variety of national brands against their store brand equivalents and in particular to see if the use of the heuristic varies according to product variety (assortment depth), hierarchy complexity (number of tiers), and product involvement. 


\section{References}

Aaker, D. (1996), Building Strong Brands, Simon and Schuster, New York.

Ailawadi, K. L., Neslin, S. A. and Gedenk, K. (2001), "Pursuing the Value-Conscious Consumer: Store Brands Versus National Brand Promotions", Journal of Marketing, Vol. 65 No. 1, pp. 71-89.

Ailawadi, K.L., and Keller, K.L (2004) . "Understanding Retail Branding: Conceptual Insights and Research Priorities" Journal of Retailing, 2004. Vol. 80, No 4, pp. 331-342.

Ailawadi, K. L., Pauwels, K. and Steenkamp, J.-B. E. M. (2008), "Private-Label Use and Store Loyalty", Journal of Marketing, Vol. 72 No. 6, pp. 19-30.

Alba, J. W., Broniarczyk, S. M., Shimp, T. A. and Urbany, J. E. (1994), "The Influence of Prior Beliefs, Frequency Cues, and Magnitude Cues on Consumers' Perceptions of Comparative Price Data", Journal of Consumer Research, Vol. 21 No. 2, pp. 219-235.

Alba, J. W., Mela, C. F., Shimp, T. A. and Urbany, J. E. (1999), "The effect of discount frequency and depth on consumer price judgments", Journal of Consumer Research, Vol. 26 No. 2, pp. 99114.

Arbuckle, J. (2012), "AMOS 20 User's Guide", Marketing Department, SPSS Incorporated.

Babin, B. J., Darden, W. R., \& Griffin, M. 1994. Work and/or Fun: Measuring Hedonic and Utilitarian Shopping Value. The Journal of Consumer Research, Vol. 20 No. 4. Pp. 644-656.

Baltas, G. and Argouslidis, P. C. (2007), "Consumer characteristics and demand for store brands", International Journal of Retail \& Distribution Management, Vol. 35 No. 5, pp. 328-341.

Baltas, G., Argouslidis, P. C. and Skarmeas, D. (2010), "The Role of Customer Factors in Multiple Store Patronage: A Cost-Benefit Approach", Journal of Retailing, Vol. 86 No. 1, pp. 37-50.

Bryant, K. W. (1990), The Economic Organisation of the Household, Cambridge University Press, Cambridge.

Burt, S. (2000), "The strategic role of retail brands in British grocery retailing", European Journal of Marketing, Vol. 34 No. 8, pp. 875.

Burt, S. and Davies, K. (2010), "From the retail brand to the retail-er as a brand: themes and issues in retail branding research", International Journal of Retail \& Distribution Management, Vol. 38 No. $11 / 12$, pp. $865-878$. 
Byrne, B. M. (2001), Structural Equation Modeling with Amos, Lawrence Erlbaum Associates, New Jersey.

Byrne, B. M., Shavelson, R. J. and Muthén, B. (1989), "Testing for the equivalence of factor covariance and mean structures: The issue of partial measurement invariance", Psychological Bulletin, Vol. 105 No. 3, pp. 456-466.

Byrne, B. M. and van De Vijver, F. J. (2010), "Testing for measurement and structural equivalence in large-scale cross-cultural studies: Addressing the issue of nonequivalence", International Journal of Testing, Vol. 10 No. 2, pp. 107-132.

Chaiken, S. (1980), "Heuristic versus systematic information processing and the use of source versus message cues in persuasion", Journal of Personality and Social Psychology, Vol. 39 No. 5, pp. 752.

Chaiken, S., Liberman, A. and Eagly, A. (1989), "Heuristic and Systematic Information Processing Within and Beyond the Persuasion Context.", in Uleman, J. and Bargh, J. A. (Eds.), Unintended Thought,. Guilford Press., New York, pp. 212-252.

Chernev, A. (2003), "When more is less and less is more: The role of ideal point availability and assortment in consumer choice", Journal of Consumer Research, Vol. 30 No. 2, pp. 170-183.

Collins, A., Kavanagh, E., Cronin, J., \& George, R. (2014). Money, mavens, time, and price search: modelling the joint creation of utilitarian and hedonic value in grocery shopping. Journal of Marketing Management, Vol. 30 No. 7-8, pp. 719-746. 10.1080/0267257X.2013.839572

Collins, A., Kavanagh, E. and George, R. (2012), "Store deal prone shoppers: motivators and implications for the supply chain in a distressed market", The International Review of Retail, Distribution and Consumer Research, Vol. 22 No. 1, pp. 83-100.

Collins, A. B. S. L. (2003), "Market sanctions, monitoring and vertical coordination within retailermanufacturer relationships: The case of retail brand suppliers", European Journal of Marketing, Vol. 37 No. 5/6, pp. 668-689.

Cuneo, A., Lopez, P. and Yagüe, M. J. (2012), "Measuring private labels brand equity: a consumer perspective", European Journal of Marketing, Vol. 46 No. 7/8, pp. 952-964.

Davidov, E., Meuleman, B., Cieciuch, J., Schmidt, P. and Billiet, J. (2014), "Measurement Equivalence in Cross-National Research", Annual Review of Sociology, Vol. 40 No. X, pp.xx.

Dawes, J. (2013), "Reasons for variation in SCR for private label brands", European Journal of Marketing, Vol. 47 No. 11/12, pp. 1804-1824.

Deleersnyder, B. and Koll, O. (2012), "Destination discount: a sensible road for national brands?", European Journal of Marketing, Vol. 46 No. 9, pp. 1150-1170.

DelVecchio, D., Henard, D. H. and Freling, T. H. (2006), "The effect of sales promotion on postpromotion brand preference: A meta-analysis", Journal of Retailing, Vol. 82 No. 3, pp. 203213. 
DeVoe, S. E. and Pfeffer, J. (2011), "Time is tight: how higher economic value of time increases feelings of time pressure", Journal of Applied Psychology, Vol. 96 No. 4, pp. 665.

Dodds, W. B., Monroe, K. B. and Grewal, D. (1991), "Effects of Price, Brand, and Store Information on Buyers' Product Evaluations", Journal of Marketing Research (JMR), Vol. 28 No. 3, pp. 307-319.

Erdem, T., Ying, Z. and Valenzuela, A. (2004), "Performance of Store Brands: A Cross-Country Analysis of Consumer Store-Brand Preferences, Perceptions, and Risk", Journal of Marketing Research (JMR), Vol. 41 No. 1, pp. 86-100.

Fornell, C. and Larcker, D. F. (1981), "Evaluating Structural Equation Models with Unobservable Variables and Measurement Error", Journal of Marketing Research (JMR), Vol. 18 No. 1, pp. $39-50$.

Garbarino, E. C. and Edell, J. A. (1997), "Cognitive Effort, Affect, and Choice", Journal of Consumer Research, Vol. 24 No. 2, pp. 147-158.

Gauri, D. K., Sudhir, K. and Talukdar, D. (2008), "The Temporal and Spatial Dimensions of Price Search: Insights from Matching Household Survey and Purchase Data", Journal of Marketing Research (JMR), Vol. 45 No. 2, pp. 226-240.

Geyskens, I., Gielens, K. and Gijsbrechts, E. (2010), "Proliferating Private-Label Portfolios: How Introducing Economy and Premium Private Labels Influences Brand Choice", Journal of Marketing Research (JMR), Vol. 47 No. 5, pp. 791-807.

González-Benito, Ó. and Martos-Partal, M. (2012), "Role of Retailer Positioning and Product Category on the Relationship Between Store Brand Consumption and Store Loyalty", Journal of Retailing, Vol. 88 No. 2, pp. 236-249.

González Mieres, C., Díaz Martín, AM., and Trespalacios Gutiérrez, J.A., (2006),"Antecedents of the difference in perceived risk between store brands and national brands", European Journal of Marketing, Vol. 40 Iss 1/2 pp. 61 - 82

Hair, J. F., Anderson, R. E., Thatham, R. L. and Black, W. C. (1995), Multivariate Data Analysis with Readings, Prentice Hall, New Jersey.

Hoch, S. J. and Banerji, S. (1993), "When Do Private Labels Succeed?", Sloan Management Review, Vol. 34 No. 4, pp. 57-67.

Hu, L. and Bentler, P. M. (1999), " Cutoff criteria for fit indexes in covariance structure analysis: Conventional criteria versus new alternatives", Structural Equation Modeling, Vol. 6 No. 1, pp. $1-55$.

IGD. (2012), Private label Update 2012, How traditional structures are evolving. In Retail Analysis, Institute of Grocery Distribution, Watford.

Kardes, F. R., Posavac, S. S. and Cronley, M. L. (2004), "Consumer inference: A review of processes, bases, and judgment contexts", Journal of Consumer Psychology, Vol. 14 No. 3, pp. 230-256. 
Kirmani, A. and Wright, P. (1989), "Money talks: Perceived advertising expense and expected product quality", Journal of Consumer Research, pp. 344-353.

Kruglanski, A. W. and Freund, T. (1983), "The freezing and unfreezing of lay-inferences: Effects on impressional primacy, ethnic stereotyping, and numerical anchoring", Journal of Experimental Social Psychology, Vol. 19 No. 5, pp. 448-468.

Lamey, L., Deleersnyder, B., Steenkamp, J.-B. E. M. and Dekimpe, M. G. (2012), "The Effect of Business-Cycle Fluctuations on Private-Label Share: What Has Marketing Conduct Got to Do with It??", Journal of Marketing, Vol. 76 No. 1, pp. 1-19.

Lichtenstein, D. R., Netemeyer, R. G. and Burton, S. (1990), "Distinguishing Coupon Proneness From Value Consciousness: An Acquisition-Transaction Utility Theory Perspective", Journal of Marketing, Vol. 54 No. (July), pp. 54-67.

Lichtenstein, D. R., Ridgway, N. M. and Netemeyer, R. G. (1993), "Price Perceptions and Consumer Shopping Behavior: A Field Study", Journal of Marketing Research (JMR), Vol. 30 No. 2, pp. 234-245.

Lindsey-Mullikin, J. and Petty, R. D. "Marketing tactics discouraging price search: Deception and competition", Journal of Business Research, Vol. 64 No. 1, pp. 67-73.

Mandrik, C. A. (1996), "Consumer Heuristics: The Tradeoff Between Processing Effort and Value in Brand Choice", Advances in Consumer Research, Vol. 23 No. 1.

Mick, D. G., Broniarczyk, S. M. and Haidt, J. (2004), "Choose, Choose, Choose, Choose, Choose, Choose, Choose: Emerging and Prospective Research on the Deleterious Effects of Living in Consumer Hyperchoice", Journal of Business Ethics, Vol. 52 No. 2, pp. 207-211.

Mitchell, V.-W. and McGoldrick, P. J. (1996), "Consumers' risk-reduction strategies: a review and synthesis", International Review of Retail, Distribution \& Consumer Research, Vol. 6 No. 1, pp. 1.

Mitra, A. (1995), "Price cue utilization in product evaluations: the moderating role of motivation and attribute information", Journal of Business Research, Vol. 33 No. 3, pp. 187-195.

Morris, D. (1979), "The strategy of own brands", European Journal of Marketing, Vol. 13 No. 2, pp. 59-78.

Nowlis, S. M. (1995), "The effect of time pressure on the choice between brands that differ in quality, price, and product features", Marketing Letters, Vol. 6 No. 4, pp. 287-295.

Nielsen (2011) Private Brands U.S. Outlook: Flash in the Pan or the Real Deal? Available at http://www.nielsen.com/content/dam/corporate/campaigns/select-summit/Private-Label-USWhite-Paper-Dec-2011.pdf. Date accessed 15-10-2014.

Nunally, J. C. (1981), Psychometric Theory, McGraw Hill., New Delhi.

Ofir, C., Raghubir, P., Brosh, G., Monroe, K. B. and Heiman, A. (2008), "Memory-Based Store Price Judgments: The Role of Knowledge and Shopping Experience", Journal of Retailing, Vol. 84 No. 4, pp. 414-423. 
Palmeira, M. M. and Thomas, D. (2011), "Two-Tier Store Brands: The Benefic Impact of a Value Brand on Perceptions of a Premium Brand", Journal of Retailing, Vol. 87 No. 4, pp. 540-548. PLMA (Private Label Manufacturer's Association) (2011), "PLMA's 2011 Private Label Trade ShowStore Brand Facts", available at http://plma.com/storeBrands/facts11.html (accessed 10th October 2014)

Podsakoff, P.M., MacKenzie, S.B., Lee, J.-Y. and N.P, Podsakoff, N.P. (2003). "Common method biases in behavioral research: A critical review of the literature and recommended remedies" Journal of Applied Psychology, Vol.88 No.5, pp. 879-903.

Putrevu, S. and Ratchford, B. T. (1997), "A Model of Search Behavior with an Application to Grocery Shopping", Journal of Retailing, Vol. 73 No. 4, pp. 463-486.

Rahman, K. and Cherrier, H. (2010), "Galloping through the Global Brandscape: Consumers in a Branded Reality", Advances in Consumer Research, Vol. 37, pp. 1.

Richardson, P., Jain, A. and Dick, A. (1996), "Household Store Brand Proneness: A Framework", Journal of Retailing, Vol. 72 No. 2, pp. 159-185.

Richardson, P. S., Dick, A. S. and Jain, A. K. (1994), "Extrinsic and intrinsic cue effects on perceptions of store brand quality", Journal of Marketing, Vol. 58 No. 4, pp. 28.

Rider, L. (2010), "The future of US Store Brands", Food Technology Magazine, available at: http://www.nielsen.com/content/dam/corporate/us/en/newswire/uploads/2010/03/0310feat_pri vatelabel.pdf (Accessed 10th October 2014).

Scitovsky, T. (1945), "Some Consequences of the Habit of Judging Quality by Price", Review of Economic Studies, Vol. 12 No. 32, pp. 6.

Sherry, J. (1998), "The Soul of the Company Store: Nike Town Chicago and the Emplaced Brandscape", in Sherry, J. F. (Ed.), Servicescapes: The Concept of Place in Contemporary Markets. McGraw-Hill, New York, pp. 109-146.

Simpson, P. M., Siguaw, J. A. and Cadogan, J. W. (2008), "Understanding the consumer propensity to observe", European Journal of Marketing, Vol. 42 No. 1/2, pp. 196-221.

Srivastava, J. and Lurie, N. (2001), "A Consumer Perspective on Price-Matching Refund Policies: Effect on Price Perceptions and Search Behavior", Journal of Consumer Research, Vol. 28 No. 2, pp. 296-307.

Steenkamp, J.-B. E. and Baumgartner, H. (1998), "Assessing measurement invariance in crossnational consumer research", Journal of consumer research, Vol. 25 No. 1, pp. 78-107.

Stigler, G. J. (1961), " The Economics of Information ", The Journal of Political Economy, Vol. 69 No. 3, pp. 213-225.

Suri, R. and Monroe, K. B. (2003), "The effects of time constraints on consumers' judgments of prices and products", Journal of consumer research, Vol. 30 No. 1, pp. 92-104. 
Szymanowski, M. and Gijsbrechts, E. (2012), "Consumption-Based Cross-Brand Learning: Are Private Labels Really Private??", Journal of Marketing Research (JMR), Vol. 49 No. 2, pp. 231-246.

Tversky, A. and Kahneman, D. (1982), "Judgement under uncertainty: Heuristics and biases", in Kahneman, D., Slovic, P. and Tversky, A. (Eds.), Judgement under uncertainty: Heuristics and biases. Cambridge University press, Cambridge:, pp. 3-20.

Urbany, J. E., Bearden, W. O. and Weilbaker, D. C. (1988), "The Effect of Plausible and Exaggerated Reference Prices on Consumer Perceptions and Price Search", Journal of Consumer Research, Vol. 15 No. 1, pp. 95-110.

Urbany, J. E., Dickson, P. A. and Kalapurakal, R. (1996), "Price Search in the Retail Grocery Market", Journal of Marketing, Vol. 60 No. 2, pp. 91-104.

Vandenberg, R. J. and Lance, C. E. (2000), "A review and synthesis of the measurement invariance literature: Suggestions, practices, and recommendations for organizational research", Organizational Research Methods, Vol. 3 No. 1, pp. 4-70.

Völckner, F. and Hofmann, J. (2007), "The price-perceived quality relationship: A meta-analytic review and assessment of its determinants", Marketing Letters, Vol. 18 No. 3, pp. 181-196.

Witham, K. (2013), "Top Private Label Trends for 2014", in Retail Analysis. Institiute of Grocery Distribution, Watford. 
Tables

Table 1. Locations of Primary Grocery Shop $(\mathrm{N}=535)$

\begin{tabular}{|l|l|l|l|l|}
\hline Retailer & \% of Sample & & Retailer & \% of Sample \\
\hline Shoprite & 29.4 & & Target & 2.0 \\
\hline Giant & 17.8 & & BJ s & 1.3 \\
\hline Acme & 14.4 & & Costco & 1.3 \\
\hline Wegmans & 5.0 & & Aldi & 1.1 \\
\hline Genuardis & 4.6 & & Sams & 0.9 \\
\hline Walmart & 3.5 & & The Fresh Grocer & 0.7 \\
\hline Pathmark & 3.1 & & Save-a-Lot & 0.6 \\
\hline SuperFresh & 3.1 & & IGA & 0.2 \\
\hline Trader Joe's & 3.0 & & Others & 5.4 \\
\hline Whole Foods & 2.4 & & Total & $\mathbf{1 0 0 . 0}$ \\
\hline
\end{tabular}


Table 2. Construct Loadings

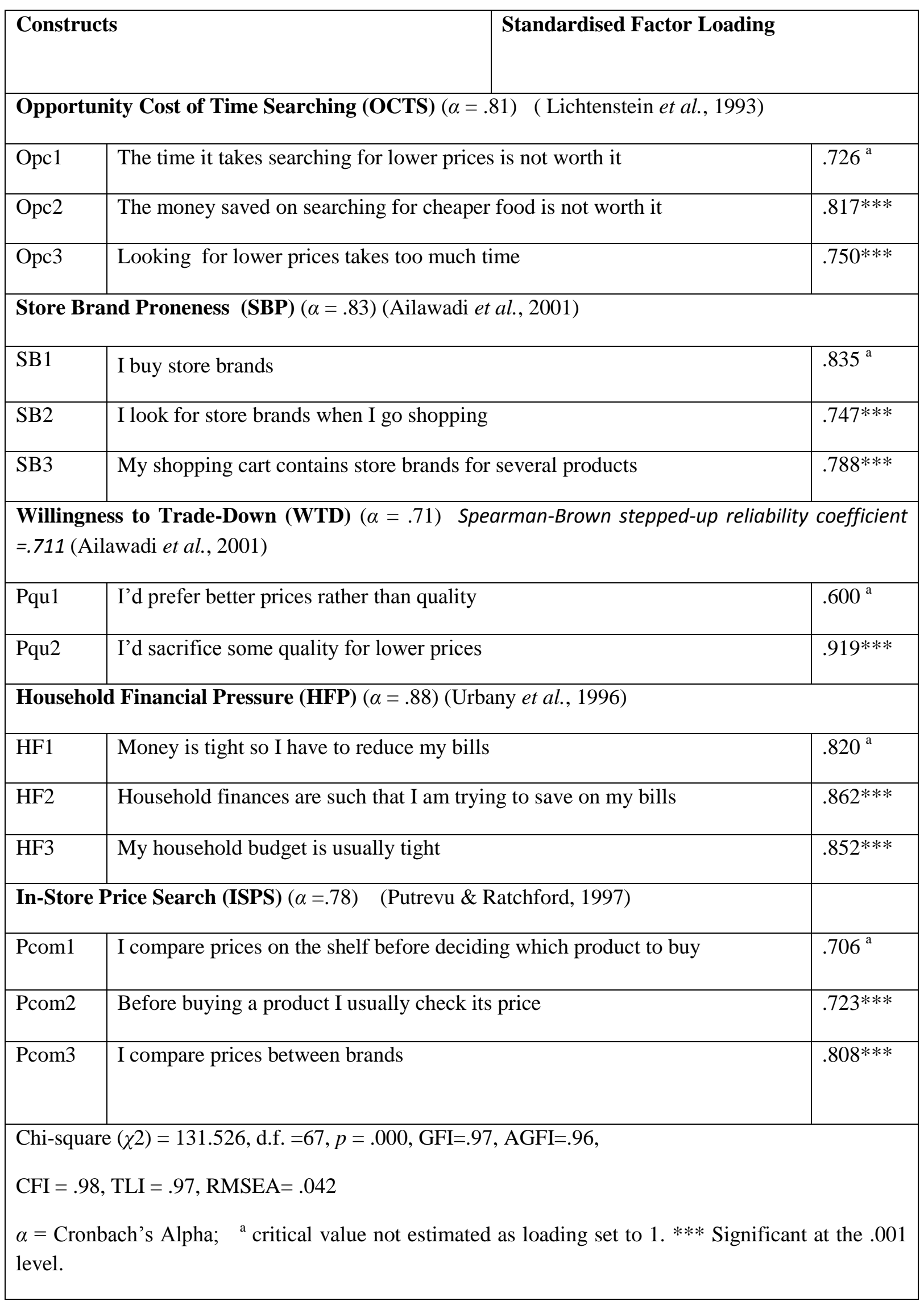


Table 3. Correlation Coefficients (upper), Average Variance Extracted (diagonal) and Squared Correlations $\mathbf{R}^{2}$ (Lower)

\begin{tabular}{|c|c|c|c|c|c|}
\hline & HFP & ISPS & OCTS & WTD & SBP \\
\hline Household Financial pressure & 0.713 & 0.410 & -0.271 & 0.300 & 0.212 \\
\hline In Store Price Search & 0.168 & 0.558 & -0.491 & 0.304 & 0.506 \\
\hline Opportunity Cost of Time & & & & & \\
\hline Searching for lower Prices & 0.073 & 0.241 & 0.586 & -0.090 & -0.101 \\
\hline Willingness to Trade Down & 0.090 & 0.092 & 0.008 & 0.600 & 0.227 \\
\hline Store Brand Proneness & 0.045 & 0.256 & 0.010 & 0.052 & 0.625 \\
\hline
\end{tabular}




\begin{tabular}{|c|c|c|c|c|c|}
\hline & & $\begin{array}{l}\text { Hyp. } \\
\text { sign }\end{array}$ & $\begin{array}{l}\text { Std } \\
\text { Path }\end{array}$ & $\mathrm{CR}$ & Outcome \\
\hline H1 & $\begin{array}{l}\text { Household Financial Pressure } \rightarrow \text { In } \\
\text { Store Price Search }\end{array}$ & + & $.242 * * *$ & 4.66 & Supported \\
\hline $\mathrm{H} 2$ & $\begin{array}{l}\text { Household Financial Pressure } \rightarrow \\
\text { Willingness to Trade Down }\end{array}$ & + & $.289 * * *$ & 4.13 & Supported \\
\hline H3 & $\begin{array}{l}\text { Willingness to Trade Down } \rightarrow \text { In Store } \\
\text { Price Search }\end{array}$ & + & $.200 * * *$ & 4.17 & Supported \\
\hline $\mathrm{H} 4$ & $\begin{array}{l}\text { Household Financial Pressure } \rightarrow \text { Store } \\
\text { Brand Proneness }\end{array}$ & + & .021 & .406 & Unsupported \\
\hline H5 & $\begin{array}{l}\text { In Store Price Search } \rightarrow \text { Store Brand } \\
\text { Proneness }\end{array}$ & + & $.600 * * *$ & 8.36 & Supported \\
\hline H6 & $\begin{array}{l}\text { Household Financial Pressure } \rightarrow \\
\text { Opportunity Cost of Time engaged in } \\
\text { Price Search }\end{array}$ & - & $-.271 * * *$ & -5.24 & Supported \\
\hline H7 & $\begin{array}{l}\text { Opportunity Cost of Time engaged in } \\
\text { Price Search } \rightarrow \text { In Store Price Search }\end{array}$ & - & $-.410 * * *$ & -7.41 & Supported \\
\hline H8 & $\begin{array}{l}\text { Opportunity Cost of Time engaged in } \\
\text { Price Search } \rightarrow \text { Store Brand Proneness }\end{array}$ & + & $.202 * * *$ & 3.37 & Supported \\
\hline & & & & & Supported \\
\hline \multicolumn{6}{|c|}{ Chi-square $(\chi 2)=132.99$ d.f. $=69, p=.000 \mathrm{GFI}=.97, \mathrm{AGFI}=.97, \mathrm{CFI}=.98, \mathrm{TLI}=.97$, } \\
\hline \multicolumn{6}{|c|}{ RMSEA $=.042$} \\
\hline *** & significant at the 0.001 level. & & & & \\
\hline
\end{tabular}


Table 5 Total, Direct, and Indirect (Standardized) Effects

\begin{tabular}{|l|c|c|c|}
\hline & $\begin{array}{c}\text { Total } \\
\text { Effect }\end{array}$ & $\begin{array}{c}\text { Direct } \\
\text { Effect }\end{array}$ & $\begin{array}{c}\text { Indirect } \\
\text { Effect }\end{array}$ \\
\hline HFP $\rightarrow$ WTD & .289 & .289 & N/A \\
\hline HFP $\rightarrow$ SBP & .213 & .021 & .192 \\
\hline HFP $\rightarrow$ ISPS & .411 & .242 & .169 \\
\hline HFP $\rightarrow$ WTD & .289 & .289 & N/A \\
\hline HFP $\rightarrow$ OCTS & -.271 & -.271 & N/A \\
\hline WTD $\rightarrow$ ISPS & .200 & .200 & N/A \\
\hline WTD $\rightarrow$ SBP & .120 & N/A & .120 \\
\hline ISPS $\rightarrow$ SBP & .600 & .600 & N/A \\
\hline OCTS $\rightarrow$ SBP & -.044 & .202 & -.246 \\
\hline OCTS $\rightarrow$ ISPS & -410 & -410 & N/A \\
\hline
\end{tabular}




\begin{tabular}{|l|l|l|l|l|l|}
\hline \multicolumn{7}{|l|}{ Table 6. Latent Means by Cluster } \\
\hline Cluster & $\mathrm{N}$ & $\begin{array}{l}\text { Financial } \\
\text { Pressure }\end{array}$ & $\begin{array}{l}\text { Standard } \\
\text { Error }\end{array}$ & $\begin{array}{l}\text { Opportunity Cost } \\
\text { of Time }\end{array}$ & Standard Error \\
\hline $\mathbf{1}$ & $\mathbf{1 3 7}$ & $\mathbf{4 . 2 4 6 0}$ & $\mathbf{. 0 3 2 8 1}$ & $\mathbf{. 7 9 3 6}$ & $\mathbf{. 0 3 2 7 3}$ \\
\hline 2 & 127 & 3.2184 & .02629 & 1.0154 & .02631 \\
\hline $\mathbf{3}$ & $\mathbf{2 0 2}$ & $\mathbf{3 . 5 0 4 0}$ & $\mathbf{. 0 4 0 4 0}$ & $\mathbf{1 . 9 7 4 9}$ & $\mathbf{. 0 2 9 6 9}$ \\
\hline 4 & 69 & 2.0202 & .04374 & 1.6648 & .09036 \\
\hline Total & 535 & 3.4348 & .03457 & 1.4046 & .02934 \\
\hline
\end{tabular}




\begin{tabular}{|c|c|c|c|c|}
\hline & $\begin{array}{l}\text { Chi- } \\
\text { square } \\
(\chi 2)\end{array}$ & d.f & P.value & $\begin{array}{l}\Delta \text { Chi-square } \\
\qquad\left(\chi^{2}\right) \\
\text { for } 1 \mathrm{d.f}\end{array}$ \\
\hline Unconstrained Model & 44.924 & 58 & .896 & \\
\hline $\begin{array}{l}\text { Constrained Model } 1 \text { (Factor Loadings fixed, } \\
\text { Paths freely estimated)) }\end{array}$ & 53.115 & 64 & .832 & 1.365 \\
\hline $\begin{array}{l}\text { Constrained Model } 2 \text { (Factor Loadings and Paths } \\
\text { fixed) }\end{array}$ & 84.126 & 70 & .120 & $5.16 *$ \\
\hline $\begin{array}{l}\text { Semi Constrained Model } 1 \\
\text { OCTS } \rightarrow \text { SBP (freely estimated) }\end{array}$ & 78.68 & 69 & .199 & $5.446^{*}$ \\
\hline $\begin{array}{l}\text { Semi Constrained Model } 2 \\
\text { OCTS } \rightarrow \text { SBP and OCTS } \rightarrow \text { ISPS (freely estimated) }\end{array}$ & 69.68 & 68 & .421 & $9.00 * *$ \\
\hline $\begin{array}{l}\text { Semi Constrained Model } 3 \\
\text { OCTS } \rightarrow \text { SBP, OCTS } \rightarrow \text { ISPS and ISPS } \rightarrow \text { SBP(freely } \\
\text { estimated) }\end{array}$ & 69.64 & 67 & .389 & 0.04 \\
\hline \multicolumn{5}{|l|}{$*$ Significant at $\alpha=.05 \quad * *$ Significant at $\alpha=.01$} \\
\hline \multicolumn{5}{|c|}{ Unconstrained Model: Chi-square $(\chi 2)=44.924$, d.f. $=58, p=.896, \mathrm{GFI}=.974$ AGFI $=951$ CFI $=1.00$, RMSEA $=.000$ AIC $=148.924$} \\
\hline \multicolumn{5}{|c|}{ Constrained Model1 Chi-square $(\chi 2)=53.115$, d.f. $=64, p=.832, \mathrm{GFI}=.969$ AGFI $=947$ CFI $=1.00$, RMSEA $=.000$ AIC $=145.115$} \\
\hline \multicolumn{5}{|c|}{ Constrained Model 2 Chi-square $(\chi 2)=84.126$, d.f. $=70, p=.12$, GFI $=.951$ AGFI $=.921$ CFI $=.981$, RMSEA $=.024$ AIC $=164.13$} \\
\hline \multicolumn{5}{|c|}{ Semi Constrained Model 1 Chi-square $(\chi 2)=78.68$, d.f. $=69, p=.199, \mathrm{GFI}=.955$ AGFI $=928$ CFI $=.987$, RMSEA $=.02$ AIC $=160.68$} \\
\hline \multicolumn{5}{|c|}{ Semi Constrained Model 2 Chi-square $(\chi 2)=69.68$ d.f. $=68, p=.421, \mathrm{GFI}=.960$ AGFI $=.935$ CFI $=1.00$, RMSEA $=1.000$ AIC $=153.68$} \\
\hline Semi Constrained Model 3 Chi-square $(\chi 2)=69.64$ d.f. $=67, p=.389, \mathrm{C}$ & $\mathrm{FI}=.96 \mathrm{AGFI}=$. & $5 \mathrm{CFI}=$ & .996 , RMSEA & $.011 \mathrm{AIC}=155.64$ \\
\hline
\end{tabular}




\begin{tabular}{|c|c|c|c|c|c|c|c|c|}
\hline & & \multicolumn{3}{|c|}{$\begin{array}{l}\text { High Financial Pressure } \\
\text { High Opportunity Cost of } \\
\text { time }\end{array}$} & \multicolumn{3}{|c|}{$\begin{array}{l}\text { High Financial Pressure } \\
\text { Low Opportunity Cost of } \\
\text { time }\end{array}$} & \\
\hline & Path & $\begin{array}{c}\text { Std } \\
\text { Regression } \\
\text { Coefficient }\end{array}$ & CR & $p$.value & $\begin{array}{c}\text { Std } \\
\text { Regression } \\
\text { Coefficient }\end{array}$ & CR & $p$.value & \\
\hline H9 & OCTS $\rightarrow$ SBP & $.381 * *$ & 2.99 & .003 & .009 & .079 & .937 & Supported \\
\hline H10 & OCTS $\rightarrow$ ISPS & .174 & 1.469 & .142 & $-.310 * *$ & -2.294 & .002 & Supported \\
\hline
\end{tabular}


List of Figures

Figure 1. A Model of Store Brand Proneness

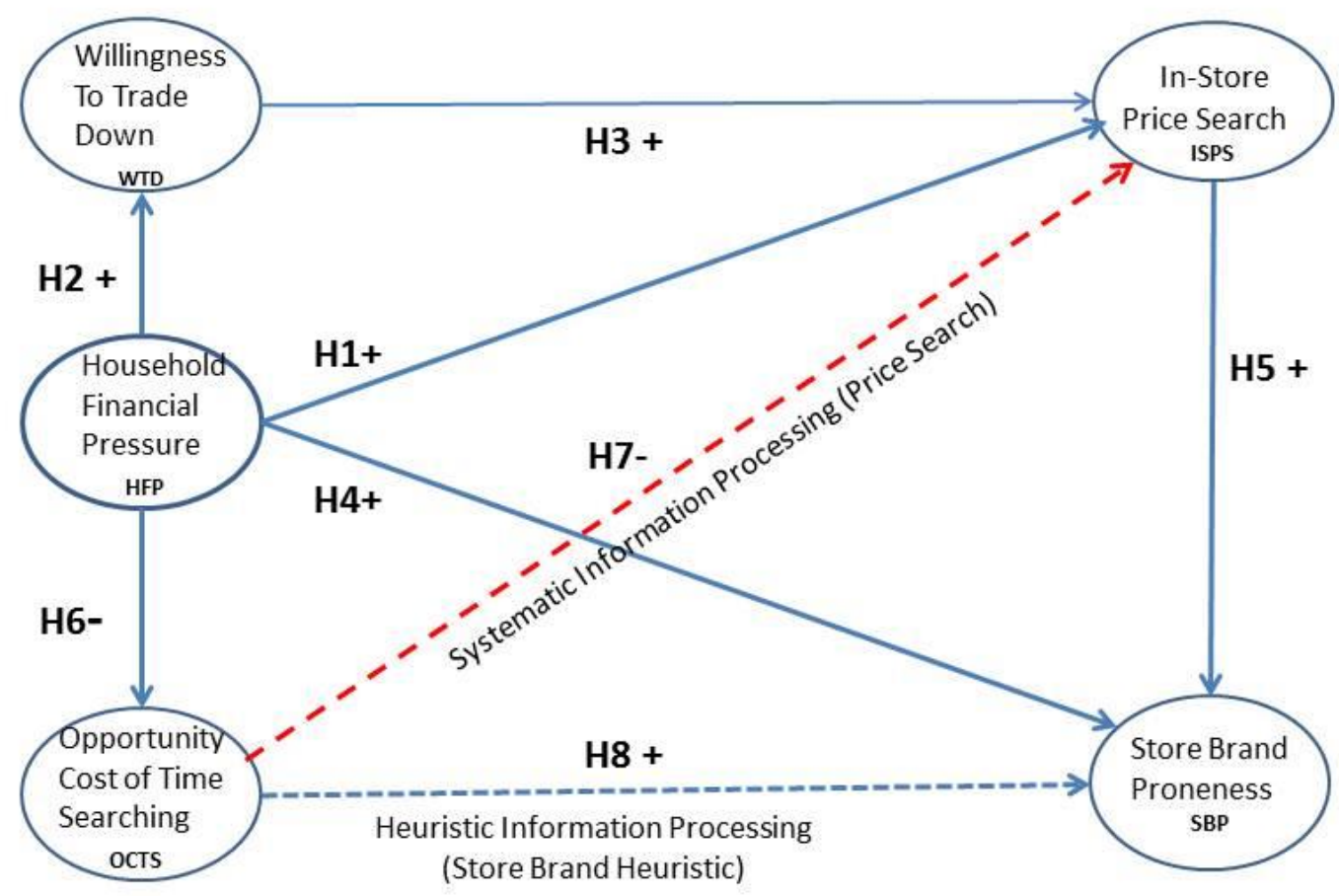


Figure 2. Systematic versus Heuristic Information Processing

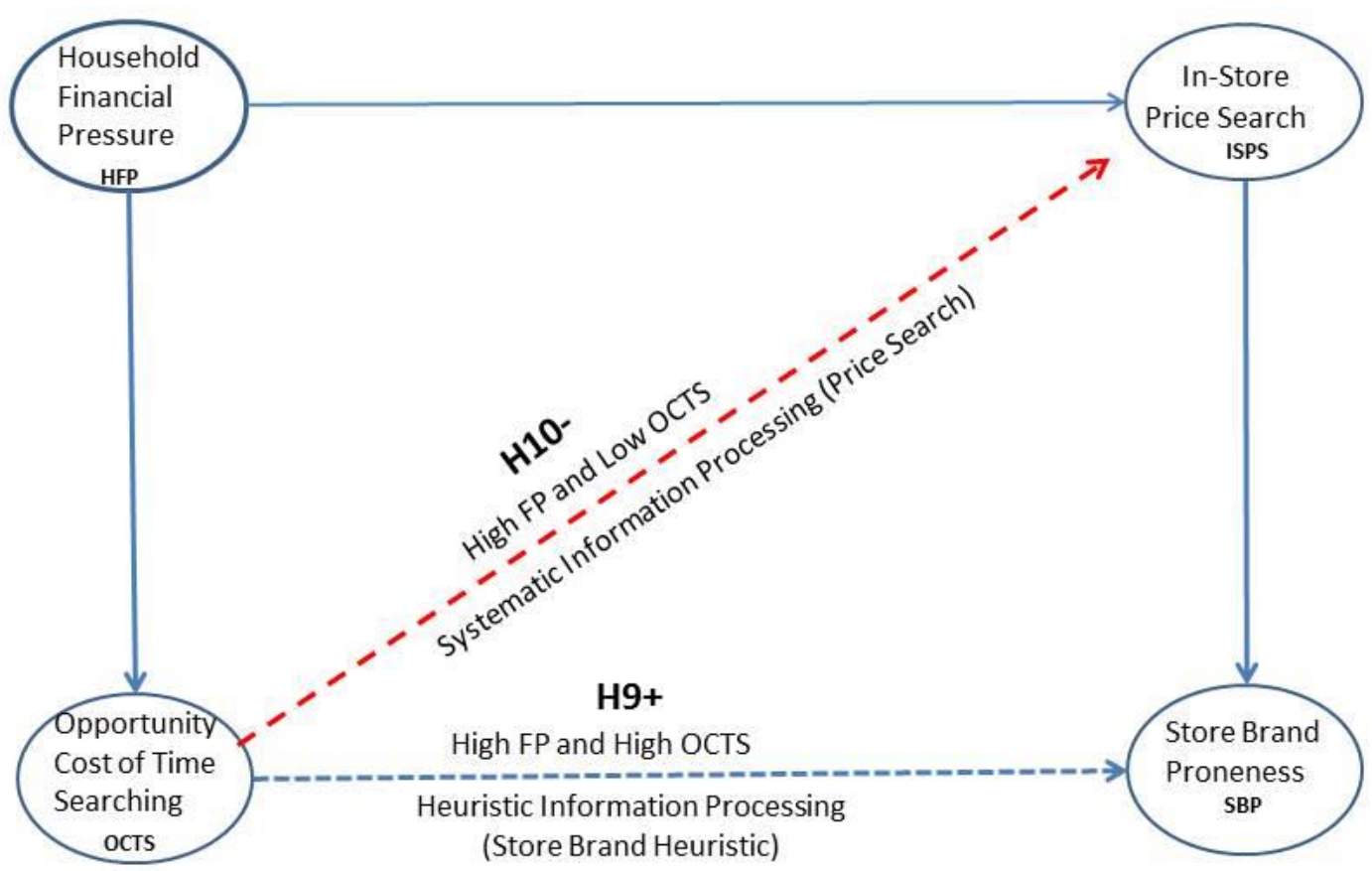

